\title{
Sports injuries in children and adolescents*
}

\author{
L. J. Micheli MD and J. D. Klein MD
}

Harvard Medical School and The Children's Hospital, Boston, USA

In recent years, we have witnessed both an increase in the participation of children and adolescents in organized sports and an increased emphasis on the fitness and skills of these young athletes. These trends have been paralleled by an increase in the number of sports-related injuries in this patient population. Many of these youngsters train in a single sports discipline, and it is this type of repetitive training which has generated new patterns of injury.

Young athletes, as with all athletes involved in organized sports, are subject to two basic types of injuries. Acute injuries are the result of single-impact macrotrauma. Overuse injuries, previously rare in this age group, are due to the repetitive microtrauma of athletic training and are presenting in far greater numbers than ever before. Children, it seems, are not only susceptible to overuse injuries, but may in fact be at increased risk as compared with their adult counterparts $^{1,2}$.

\section{Types of injury}

The spectrum of macrotrauma sustained by young athletes includes fractures, ligament sprains, musculotendinous strains, and soft tissue contusions. The early management of these injuries is governed by the principles of general paediatric orthopaedic trauma. Complete rehabilitation, however, requires the restoration of both strength and range of movement and has as its goal the expedient but safe return to athletic competition ${ }^{3,4}$. Central to this is the concept of 'relative rest' ${ }^{5}$. The athlete must strive to maintain the movement and conditioning of both the injured part and the body as a whole, within the limits of appropriate treatment.

Overuse injuries in sports-active children are divided into four broad categories and include stress fractures, tendinitis and traction apophysitis of tendon insertions, bursitis, and joint disorders 1 .

Stress fractures represent the failure of cortical bone subjected to repetitive loading. Often the history reveals increases or changes in the training

* Based on the Annual Guest Lecture, 1989, The London Sports Medicine Institute

Address for correspondence: Dr Lyle J. Micheli MD, Director, Division of Sports Medicine, The Children's Hospital, 300 Longwood Avenue, Boston, MA 02115, USA

(C) 1991 Butterworth-Heinemann Ltd. 0306-3674/91/010006-04 regimen. Though plain films are generally negative for $6-8$ weeks, ${ }^{99 \mathrm{~m}} \mathrm{Tc}$ bone scans can confirm the diagnosis as early as 3-5 days after onset of symptoms $^{6}$ (Figure 1).

Though tendinitis and bursitis can be seen in the young athlete, traction apophysitis is more characteristic of this patient population. Osgood-Schlatter disease of the tibial tubercle is an example of such a condition and represents a chronic avulsion injury secondary to tight muscle-tendon units in the growing child ${ }^{7}$. Treatment includes a period of relative rest along with a directed programme of quadriceps stretching and strengthening.

Disorders of the joint surface are an extremely common and disabling problem in the young athlete. Osteochondritis dissecans represents a repetitive

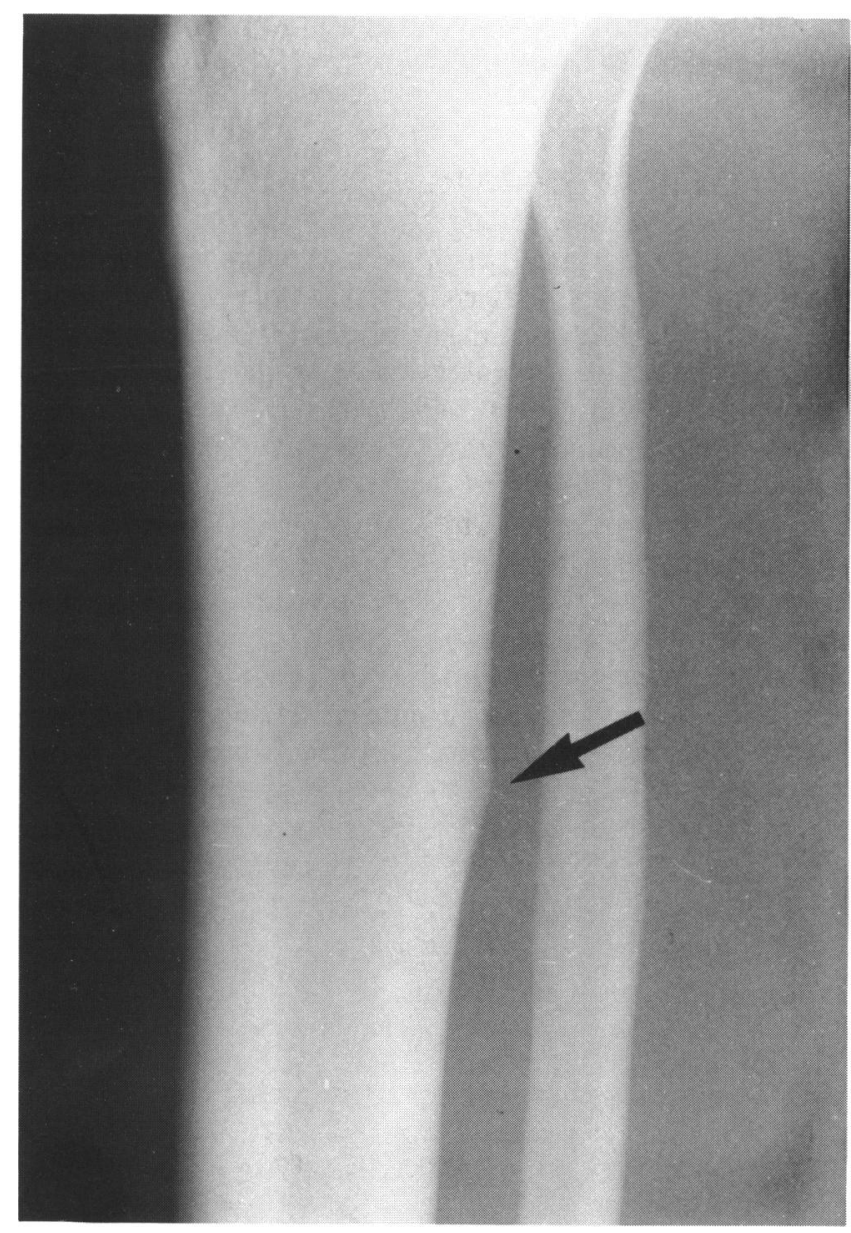

Figure 1. This 'skin-splint' in a young runner was in actuality a stress fracture 
Table 1. Risk factors for overuse injury
Growth

Training error

Muscle-tendon imbalance

Anatomical malalignment

Improper footwear
Playing/running surface Poor nutrition

Cultural deconditioning Psychological factors Associated disease state

injury to the subchondral bone and overlying articular cartilage; it reflects the particular sensitivity of the paediatric joint surface to shear stress ${ }^{8,9}$. Overuse of the articular cartilage can also lead to chondromalacia, though this pattern of articular cartilage injury is more characteristic of fully mature cartilage.

Diagnosis of these disorders requires both knowledge of the various types of injuries encountered in different sports disciplines and a careful history and physical examination. At the Sports Medicine Division of the Boston Children's Hospital, we attempt to identify predisposing risk factors as an aid to the diagnosis, treatment, and prevention of overuse injuries in the paediatric athlete ${ }^{1,10}$ (Table 1). Following this scheme, the vast majority of these injuries are treated conservatively with a short period of relative rest and correction of any detected underlying risk factors. Emphasis, once again, is on maintenance of flexibility and muscle tone while the healing process ensues ${ }^{11}$.

\section{Risk factors}

\section{Growth}

Growth is a central factor in the development of overuse injuries in young athletes. Growth cartilage in the immature skeleton is found at the epiphyseal growth plate, the articular surface, and the apophyseal insertions ${ }^{1}$ (Figure 2). Biomechanical and clinical evidence suggests that growth cartilage, especially that of the articular surface, is less resistant to repetitive microinjury than the mature adult counterpart ${ }^{2}$. Other authors suggest that repetitive microtrauma to the epiphyseal plate may predispose to later degenerative arthritis of the hip based on subclinical slippage of the femoral capital epiphysis $^{12,13}$.

Growth itself poses another risk factor for athletic injury. The soft tissues elongate passively in response to the longitudinal growth of the bones and thus become progressively tighter, especially during periods of rapid growth ${ }^{1,14}$. This decreased flexibility predisposes the young athlete to injury and should be addressed by a programme of prophylactic stretching during the growth spurt.

\section{Training error}

Abrupt changes and unsound increases in intensity of training clearly predispose to overuse injury ${ }^{15}$. Poorly trained coaches and overzealous parents must share the blame with the athletes in this regard ${ }^{16}$. In general, increasing the duration or intensity of training more than $10 \%$ per week should be avoided.

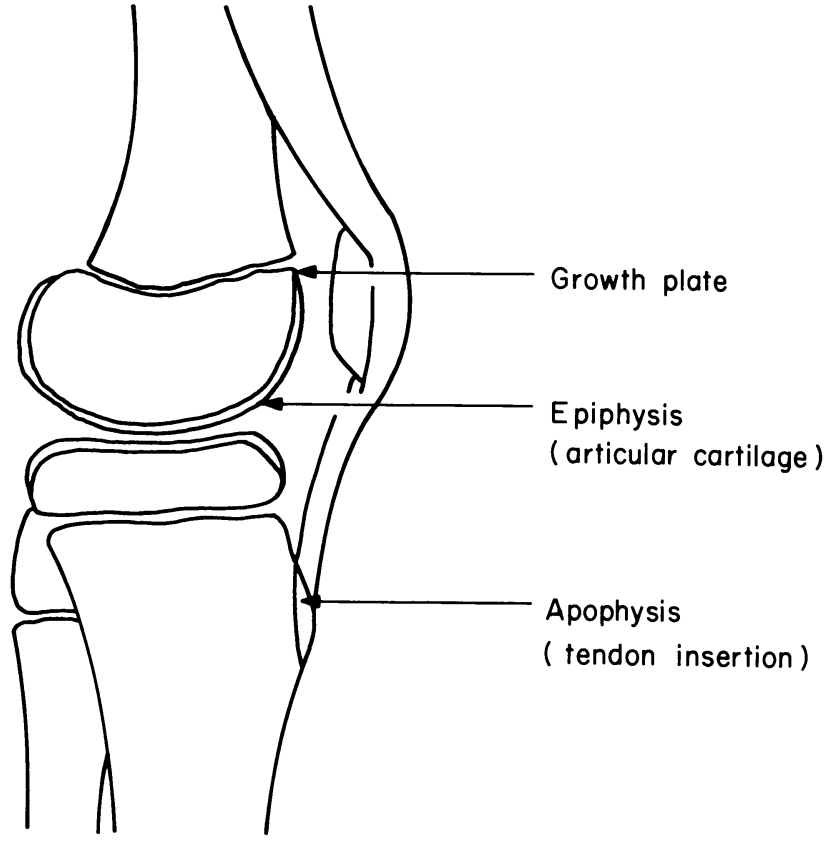

Figure 2. Location of growth cartilage. (Reproduced with permission of Orthop Clin North Am 1983; 14: 341; W. B. Saunders, Philadelphia, USA)

\section{Muscle-tendon imbalance}

As noted previously, the adolescent growth spurt is accompanied by decreased flexibility and increased risk of overuse injury. Traction apophysitis has already been mentioned. Young throwing athletes also seem prone to chronic anterior subluxation of the shoulder. This may reflect contracture of the posterior capsule as a result of chronic overhead use with secondary anterior laxity ${ }^{2}$. Treatment consists 'of stretching the posterior capsule and strengthening the anterior structures to establish overall muscletendon balance.

\section{Anatomical malalignment}

Malalignments include excessive femoral anteversion, leg length discrepancies, patellar malalignment, genu varum or valgum, and pes planus. Excessive femoral anteversion is extremely common and may predispose to patellofemoral joint problems ${ }^{17}$. Though these conditions may contribute to injury in the young athlete, anatomical malalignment is generally well tolerated by the body and thus care must be taken not to overlook other important risk factors $^{18,19}$.

\section{Footwear and playing surface}

Proper running shoes must provide support and impact absorption as well as protection from hyperpronation. The relative hardness of the playing surface is yet another factor as subtle changes to harder surfaces often seem to predispose the young athlete to overuse injury ${ }^{20}$. 


\section{Nutrition}

Recent studies have detected deficiencies of calcium and vitamins in the diet of amenorrhoeic ballet dancers, gymnasts, and distance runners ${ }^{21}$. Many amenorrhoeic athletes also have decreased bone mineral density and a corresponding increased incidence of stress fractures ${ }^{22}$.

\section{Cultural deconditioning}

Numerous factors account for the general decline in the physical fitness of children in the USA. Parents are increasingly concerned for the safety of their children outside the home. Inside the home, children spend $25-40 \mathrm{~h}$ each week with television and video games $^{23}$. It is no surprise, then, that national surveys document significant increases in paediatric obesity in the USA ${ }^{24}, 25$. One study reported in the September 1990 issue of the Journal of the American Medical Association demonstrated that obesity in young children correlates with poor aerobic fitness and hypertension, which is thought to predispose to later cardiovascular disease ${ }^{26}$.

\section{Associated disease}

Sports-active youngsters are subject to the same non-traumatic conditions as their non-sports-active counterparts. Infection, neoplasm, and inflammatory arthritis must always be remembered. Slipped femoral capital epiphysis and Perthes' disease must be considered in patients with hip and/or knee pain. A discoid lateral meniscus may present as chronic knee pain with mechanical symptoms. A history of multiple ankle sprains and subtalar joint stiffness on physical examination is suspicious for a tarsal coalition. Finally, scoliosis, though generally painless, must not be overlooked by the examining physician.

\section{Psychological factors}

Although some athletes thrive on the stress of competition, there is a clinical impression that youngsters under psychological stress are predisposed to injury ${ }^{27}$. Among those young athletes who are injured, there seems to be an increase in the number of patients diagnosed with post-traumatic pain syndrome, or reflex sympathetic dystrophy (RSD) ${ }^{28-30}$. Previously, this entity was described primarily in adults. The experience at the Sports Medicine Division of the Boston Children's Hospital has suggested that psychological issues may be an important factor in the development of this condition in the sports-active child ${ }^{27}$.

\section{Prevention}

Prevention of musculoskeletal injury is based largely on the careful assessment of the aforementioned risk factors. The physical examination and preparticipation evaluation offers the opportunity to intervene in this regard. The overall fitness, flexibility, and medical condition of each sports candidate can be assessed and then measured against the demands of their potential sport. A training regimen can then be prescribed in order to address specific deficiencies in strength and flexibility.

The central importance of flexibility must be stressed in the young athlete, especially during periods of rapid growth. Stretching exercises should be performed with the muscles 'warm' to decrease the risk of injury ${ }^{15}$.

Strength training also can be helpful in preventing sports injuries in youngsters, provided it is performed under close supervision ${ }^{15}$. Contrary to earlier reports ${ }^{31}$, such training programmes can be quite safe. Emphasis must be placed on proper warm-up, stretching, and high numbers of repetitions with a low weight ${ }^{32}$.

Proper instruction and quality coaches must be made available for children in organized sports. Although our own volunteer coaches are wellmeaning, most are unaware of the young athlete's particular susceptibility to injury. Hence, our most vulnerable athletes are generally trained by our least experienced coaches.

Parents must play an active role by verifying the certification of their children's coaches. They must also ensure that appropriate protective equipment is provided. Though no substitute for proper instruction and supervision, items such as shin guards in football, face masks in hockey, and helmets in cycling have all helped reduce the incidence of injury in young athletes ${ }^{33}$.

The upper and lower limits of safe athletic training for children are still unclear. Guidelines for training programmes must emphasize the maintenance of flexibility and the need for slow, progressive increase in training and intensity. The ' $10 \%$ per week' rule for increasing training intensity is now widely accepted and is particularly important in the development of young athletes ${ }^{32}$. Most importantly, children should be allowed to enjoy sports participation, and wellintended but misdirected parents and coaches must not pressure a child who is uncomfortable with the rigours of competitive activity.

\section{References}

1 Micheli LJ. Overuse injuries in children's sports: the growth factor. Orthop Clin North Am 1983; 14(2): 337-60.

2 O'Neill DB, Micheli LJ. Overuse injuries in the young athlete. Clin Sports Med 1988; 7: 591-610.

3 Jackson DW, Jarrett H, Bailey D, Kausek J, Swanson J, Powell JW. Injury prediction in the young athlete: a preliminary report. Am J Sports Med 1978; 6: 6-16.

4 Nicholas JA. Risk factors, sports medicine, and the orthopaedic system: an overview. J Sports Med 1976; 3: 243.

5 Micheli LJ. Special considerations in children's rehabilitation programs. In: Hunter FY, Funk FJ, eds. Rehabilitation of the Injured Knee. St. Louis: C.V. Mosby, 1984: 406-13.

6 Rosen PR, Micheli LJ, Treves S. Early scintigraphic diagnosis of bone stress and fractures in athletic adolescents. Pediatrics 1982; 70: 11-5.

7 Ogden JA, Southwick WD. Osgood-Schlatter's disease and tibial tubercle development. Clin Orthop 1976; 116: 180-9.

8 Canale ST, Belding RM. Osteochondral lesions of the talus. J Bone Joint Surg [Am] 1980; 62-A: 97-102.

9 Lipscomb AB. Baseball pitching in growing athletes. J Sports Med 1975; 3: 25-34.

10 Micheli LJ. Lower extremity overuse injuries. Acta Med Scand Suppl 1986; 711: 171-7. 
11 Stanish WD. Overuse injuries in adolescents: a perspective. Med Sci Sports Exerc 1984; 16: 1-7.

12 Chantraine A. Osteoarthritis and axis deviation of the knee joint in soccer players. Med Sci Sports Exerc 1982; 14: 130

13 Murray RO, Duncan C. Athletic activity in adolescence as an etiological factor in degenerative hip disease. J Bone Joint Surg [Br] 1971; 53-B: 406-19.

14 Malina RN. Adolescent changes in size, build, composition, and performance. Hum Biol 1974; 46: 117.

15 Rooks DS, Micheli LJ. Musculoskeletal assessment and training: the young athlete. Clin Sports Med 1988; 7: 641-77.

16 Gross $\mathrm{RH}$. Training programs for volunteer coaches: more time, more money. Phys Sportsmed 1982; 11: 183-5.

17 Micheli LJ, Slater JA, Woods E, Gerbino PG. Patella alta and the adolescent growth spurt. Clin Orthop 1986; 213: 159-62.

18 Gross RH. Leg length discrepancy: how much is too much? J Orthop 1978; 1: 307-10.

19 Micheli LJ, Smith AD. Sports injuries in children. Curr Probl Pediatr 1982; 12: 1-54.

20 Micheli LJ. Pediatric and adolescent sports injuries: recent trends. In: Pandolph K, ed. Exercise and Sport Sciences Reviews, Vol. 14. New York: Macmillan Publishing, 1986: 359-74.

21 Warren MP. Excessive dieting and exercise: the dangers for young athletes. I Musculoskel Med 1987; 4: 31-40.

22 Lloyd T, Triantafyllou SJ, Baker ER et al. Women athletes with menstrual irregularity have increased musculoskeletal injuries. Med Sci Sports Exerc 1986; 18: 374-9.
23 Dietz WM, Gortmaker SL. Do we fatten our children at the television set? Obesity and television-viewing children and adolescents. Pediatrics 1985; 75: 807-12.

24 Gortmaker SL, Dietz WM, Sobol AM, Wehler CA. Increasing pediatric obesity in the United States. Am J Dis Child 1987; 141: $535-40$.

25 Summary of Findings from National Children and Youth Fitness Study. US Department of Health and Human Services, Office of Disease Prevention and Health Promotion, 1985.

26 Guten B, Basch C, Shea $S$ et al. Blood pressure, fitness and fatness in 5- and 6-year-old children. JAMA 1990; 284: 1123-7.

27 Pillemer FG, Micheli LJ. Psychological considerations in youth sports. Clin Sports Med 1988; 7: 679-89.

28 Foster RS, Fu FH. Reflex sympathetic dystrophy in children. Orthopedics 1985; 8: 475-80.

29 Ruggeri SB, Athreya BH, Doughty R, Gregg JR, Das MM. Reflex sympathetic dystrophy. Clin Orthop 1982; 163: 225-30.

30 Silber TJ, Majid M. Reflex sympathetic dystrophy syndrome in children and adolescents: report of 18 cases and review of the literature. Am J Dis Child 1988; 142: 1325-30.

31 Brady TA, Cahill BR, Bodnar LM. Weight training-related injuries. Am J Sports Med 1982; 10: 1-5.

32 Sewall L, Micheli LJ. Strength training for children. J Pediatr Orthop 1986; 6: 143-6.

33 Micheli LJ. The exercising child: injuries. Pediatr Exerc Sci 1989; 1: 329-35. 